\title{
Correction to: Impact of the Interval Between Neoadjuvant Chemotherapy and Gastrectomy on Short- and Long-Term Outcomes for Patients with Advanced Gastric Cancer
}

\begin{abstract}
Augustinas Bausys, $\mathrm{MD}^{1,2}$ (D) Toomas Ümarik, $\mathrm{MD}^{3}$, Martynas Luksta, $\mathrm{MD}^{\mathbf{1}}$, Arvo Reinsoo, $\mathrm{MD}^{3}$, Rokas Rackauskas, MD, $\mathrm{PhD}^{1}$, Giedre Anglickiene, $\mathrm{MD}^{4}$, Marius Kryzauskas, $\mathrm{MD}^{1}$, Kristina Tõnismäe, $\mathrm{MD}^{5}$, Veslava Senina, $\mathrm{MD}^{6}$, Dmitrij Seinin, $\mathrm{MD}^{6}$, Rimantas Bausys, MD, PhD ${ }^{1,2}$, and Kestutis Strupas, MD, $\mathbf{P h D}^{1}$

${ }^{1}$ Clinic of Gastroenterology, Nephrourology, and Surgery, Institute of Clinical Medicine, Faculty of Medicine, Vilnius University, Vilnius, Lithuania; ${ }^{2}$ Department of Abdominal Surgery and Oncology, National Cancer Institute, Vilnius, Lithuania; ${ }^{3}$ Upper Gastrointestinal Tract Surgery Department, North Estonia Medical Centre, Tallinn, Estonia; ${ }^{4}$ Department of Medical Oncology, National Cancer Institute, Vilnius, Lithuania; ${ }^{5}$ Pathology Department, North Estonia Medical Centre, Tallinn, Estonia; ${ }^{6}$ National Centre of Pathology, Affiliate of Vilnius University Hospital Santaros Klinikos, Vilnius, Lithuania
\end{abstract}

CORRECTION TO: ANN SURG ONCOL (2021) 28:4444-4455 HTTPS://DOI.ORG/10.1245/S10434-020-09507-1

The original online version of this article has been updated. The Conclusions section of the Abstract was corrected.
Publisher's Note Springer Nature remains neutral with regard to jurisdictional claims in published maps and institutional affiliations.

The original article can be found online at https://doi.org/10.1245/ s10434-020-09507-1.

(C) Society of Surgical Oncology 2021

Published Online: 15 July 2021

A. Bausys, MD

e-mail: abpelikanas@gmail.com 